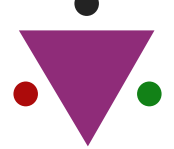

IJCRR

Section: Healthcare Sci. Journal Impact Factor: $6.1(2018)$ ICV: 90.90 (2018)

(c) (1) (3)

Copyright@IJCRR

\title{
Significance of Neutrophil Lymphocyte Ratio and High Sensitivity C-Reactive Protein in Type 2 Diabetic Patients
}

\author{
A. Velayutharaj ${ }^{1}$, R. Saraswathi ${ }^{1}$, L. Muthumani ${ }^{3}$, R. Shivakumar ${ }^{4}$, M. Sivakumar ${ }^{5}$ \\ 'Associate Professor, Department of Biochemistry, Trichy SRM Medical College Hospital \& Research Centre, Tiruchirapalli, Tamilnadu-621105, \\ India; ${ }^{2}$ Associate Professor, Department of Microbiology, Trichy SRM Medical College Hospital \& Research Centre, Tiruchirapalli,

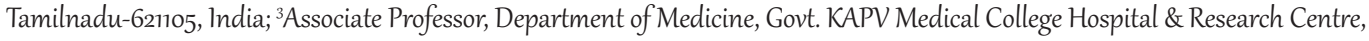 \\ Tiruchirapalli, Tamilnadu-620002, India; ${ }^{4}$ Professor, Department of Pharmacology, Trichy SRM Medical College Hospital \& Research Centre, \\ Tiruchirapalli, Tamilnadu-621105, India; ${ }^{5}$ Consultant Physician, Saraswathi Hospital, Pullambadi, Tiruchirapalli, Tamilnadu-621711, India.
}

\section{ABSTRACT}

Introduction: Low-grade inflammation is the basic pathophysiology in metabolic syndrome and the development of T2DM. Previous studies have demonstrated that increased neutrophil-lymphocyte ratio (NLR) is a marker of cardiovascular disease and cancer. Apart from many inflammatory markers, NLR is believed to be the balance between innate (neutrophils) and adaptive (lymphocytes) immune system responses to the low-grade inflammation.

Methods: The present study was to find the relationship between NLR and hsCRP (High sensitive C reactive protein) in patients with T2DM in a tertiary care centre. Age and sex-matched 60 T2DM patients (males 32, female 28) were included in this study. After getting the written informed consent $5 \mathrm{ml}$ of fasting blood sample was collected for the analysis of fasting blood glucose, Total, differential WBC count and High sensitive Creative protein.

Results: Our study showed that there is a strong positive correlation between increased NLR and hsCRP.357 ( $p \leq 0.005)$. Here, it is important to note that, males have low levels of hsCRP $(2.63 \pm 3.23)$ than females $(4.82 \pm 4.16)$ and these changes are also statistically significant ( $\mathrm{p} \leq 0.026)$.

Conclusion: The White blood cell count is one of the markers of subclinical inflammation. In diabetes, due to the presence of low-grade inflammation, the white cell count, NLR and hsCRP were increased. Hence, by assessing NLR, which is a simple clinical investigation will be useful in T2DM patients to control future vascular risk events.

Key Words: White blood cell (WBC) count, Neutrophil lymphocyte ratio (NLR), Type 2 diabetes mellitus (T2DM), High sensitive C-reactive protein (hsCRP)

\section{INTRODUCTION}

Diabetes mellitus is one among the chronic metabolic disorder with increasing prevalence all over the world, in particular, South-East Asia. It has been reported by the IDF, 2017 that the prevalence of Diabetes in India is around 8.79 and projected that to be 11.4 during the year 2045 in the adult population (72.9 million to 134.3 million - age of 20 to 79 years). Diabetes and its complications not only affect the health and wealth of the population but also affect the economics and growth of the country because of the increase in financial burden. If we aware of novel markers of inflammation to find out the disease early, we can postpone the complications or even can reduce the complications with proper intervention.
Many studies have proven that Neutrophil Lymphocyte ratio (NLR) which is nothing but the subtraction of absolute neutrophil count to absolute lymphocyte count is a simple investigation, but with lots of information regarding the disease status in diabetes mellitus. ${ }^{1}$ There was a significant association between NLR with Insulin resistance (IR) and high NLR values may be considered as a potential predictive marker of IR. ${ }^{2}$

Low-grade inflammation is the basic Pathophysiology in metabolic syndrome and the development of T2DM. Apart from many inflammatory markers, NLR is believed to be the balance between innate (neutrophils) and adaptive (lymphocytes) immune system responses to the low-grade inflammation.,

\section{Corresponding Author:}

A. Velayutharaj, Associate Professor, Department of Biochemistry, Trichy SRM Medical College Hospital \& Research Centre, Tiruchirapalli, Tamilnadu-621105, India; Email: drvelsiva@gmail.com

ISSN: 2231-2196 (Print)

Received: 24.09 .2020
ISSN: $0975-5241$ (Online)

Revised: 15.10 .2020
Accepted: 04.11 .2020
Published: 24.11 .2020 
Previous researches have been proved that elevated NLR is associated with increased concentration of various pro-inflammatory cytokines which may cause cellular DNA damage. ${ }^{5-7}$

Cardiovascular disease, which is an inflammatory disease, the use of hs-CRP appears to represent a valid tool to identify people at risk of cardiovascular disease. ${ }^{8}$ Many studies have proven that hs-CRP is an important inflammatory marker of cardiovascular disease risk and is relating to the pathophysiology of atherosclerosis, providing additional importance in the prevention of future events. ${ }^{9}$

The present study was to find the relationship between Neutrophil Lymphocyte Ratio (NLR) and inflammatory marker high sensitive C-reactive protein (hsCRP) in patients with $\mathrm{T} 2 \mathrm{DM}$ in a tertiary care teaching centre.

\section{MATERIALS AND METHODS}

Age and sex-matched 60 T2DM patients (males 32, female 28) were included in this study. Patients who are on chemotherapy, steroids, antibiotics, immunomodulators, haematological disorders, T1DM, GDM were excluded from this study. Also the patients who were on statin therapy and Nonsteroidal anti-inflammatory drugs (NSAIDs).

After getting the written informed consent $5 \mathrm{ml}$ of fasting blood sample was collected for the analysis of Fasting blood glucose, Lipid profile, Total \& Differential WBC count and High sensitive Creative protein (hsCRP). Biochemical parameters were done on Cobas e311 auto analyzer and Cell count was done in Mindray BS5300, CBC analyzer. Results were analyzed by using SPSS 16.0 version. Student $t$-test and Pearson Correlation have been used for statistical analysis.

Results were analyzed in the SPSS 16.0 version. Student t-test and Pearson correlation were used for the statistical analysis of parameters.

\section{RESULTS}

In this study, 32 males and 28 females study parameter were analyzed with a mean age group of 46.75 (Males, SD 11.08) and 52.17 (Females, SD 12.53). The total WBC count has been increased in females than Males which is statistically significant $(p \leq 0.039)$. And it has been found that there is a strong positive correlation between increased NLR and hsCRP $\rightarrow .357(\mathrm{p} \leq 0.005)$. Here, an interesting point to note that, males have low levels of hsCRP $(2.63 \pm 3.23)$ than females $(4.82 \pm 4.16)$. These changes are also statistically significant $(\mathrm{p} \leq 0.026)$.

As for as Diabetic parameters are concerned, there is no correlation between Fasting blood glucose (FBG) and NLR, hsCRP but correlated with the total WBC count. But as for as Glycated haemoglobin $(\mathrm{HbAlc} \%)$ is concerned not cor- related and statistically also not significant. Using widely available high-sensitivity assays, CRP levels of $<1,1$ to 3 , and $>3 \mathrm{mg} / \mathrm{L}$ corresponds to low-, moderate-, and high-risk groups for future cardiovascular events.

\section{DISCUSSION}

The neutrophil-to-lymphocyte ratio (NLR) can be obtained by dividing absolute neutrophil to absolute lymphocyte count is a novel simple and inexpensive test for assessing inflammation..$^{10}$ There are many strong pieces of evidence suggested that increased NLR has been stated as a potential marker of poor prognosis in multiple tumours ${ }^{11-13}$ and cardiovascular diseases ${ }^{14-16}$ in the general population. Isaac et al. reported that increased NLR has been associated with mortality among multiple chronic medical disorders. ${ }^{17}$

Our study has proved that diabetic patients have a significantly elevated NLR compared with non-diabetic subjects which are consistent with earlier studies which have stated that increased $\mathrm{HbAlc}$ might be associated with increased NLR in patients with type 2 diabetes mellitus. ${ }^{18,19}$ Many studies have shown total white blood cell (WBC) counts as an independent risk marker for diabetes cases, impaired insulin sensitivity, Metabolic Syndrome, or coronary artery disease (CAD) White blood cell (WBC) count and high sensitivity C-Reactive Protein (hs-CRP) were more useful biomarkers to indicate inflammation in the obesity and Metabolic syndrome (MetS) severity. ${ }^{20}$

Many numbers of studies revealed that NLR is a useful marker of diabetes-related to not only macrovascular but also microvascular complications, increased NLR levels may be associated with microvascular complications of DM in the elderly population. ${ }^{21}$ Inflammatory marker NLR significantly increases in prediabetic and diabetic patients. NLR and Platelet lymphocyte ratio (PLR) values may be reliable predictive markers in prediabetes and diabetes mellitus. ${ }^{22}$ NLR is inexpensive, easy to use, a reliable predictor of nephropathy, retinopathy, and CAD in Indian T2DM. ${ }^{23}$ The results of our study show that there was a significant relation between NLR and diabetic nephropathy. Therefore, NLR may be considered as a novel surrogate marker of diabetic nephropathy in the early stages. ${ }^{24}$ The NLR available also as a marker of inflammation which is cheaper and an important predictor of complications especially microvascular in type 2 diabetes patients. ${ }^{25}$ It has been stated that increased NLR level is associated with elevated HbA1c and poor glycemic control in patients with type 2 diabetes mellitus and it can be used as a monitoring tool during the follow up of diabetic patients. ${ }^{26}$

\section{CONCLUSION}

Total White blood cell count, which has been proven that as one of the markers of subclinical inflammation and because 
of the low-grade inflammation in diabetes, the White blood cell count, NLR and hsCRP were increased. By assessing NLR, which is a simple clinical investigation will be useful in T2DM patients to control future cardiovascular risk events, microvascular complications. It can also be a useful marker even to predict the presence of Cardiovascular disease in type 2 diabetic patients along with hsCRP measurement and our study supports the use of NLR as a cost-effective biomarker to predict the future cardiovascular risk and a large scale study is needed for the further establishment of it.

\section{ACKNOWLEDGEMENT}

Authors acknowledge the immense help received from the scholars whose articles are cited and included in references to this manuscript. The authors are also grateful to authors/ editors/publishers of all those articles, journals and books from where the literature for this article has been reviewed and discussed.

\section{Conflict of Interest: Nil}

\section{Source of Funding: Nil}

\section{REFERENCES}

1. Xu T, Weng Z, Pei C, Yu S, Chen Y, Guo W, et al. The relationship between neutrophil-to-lymphocyte ratio and diabetic peripheral neuropathy in Type 2 diabetes mellitus. Medicine (Baltimore) 2017; 96(45): e8289.

2. Lou M, Luo P, Tang R, Peng Y, Yu S, Huag W, et al. Relationship between neutrophil-lymphocyte ratio and insulin resistance in newly diagnosed type 2 diabetes mellitus patients. BMC Endocr Disord 2015;15:9.

3. Donath MY, Shoelson SE. Type 2 diabetes as an inflammatory disease. Nat Rev Immunol 2011;11:98-107.

4. Xu H, Barnes GT, Yang Q, et al. Chronic inflammation in fat plays a crucial role in the development of obesity-related insulin resistance. J Clin Invest. 2003;112:1821-1830.

5. Guthrie GJ, Charles KA, Roxburgh CS, Horgan PG, McMillan DC, Clarkeet SJ et al. The systemic inflammation-based neutrophil-lymphocyte ratio: experience in patients with cancer. Crit Rev Oncol Hematol 2013;88(1): 218-230.

6. Motomura T, Shirabe K, Mano Y, Muto J, Toshima T, Umemoto Y, et al. Neutrophil-lymphocyte ratio reflects hepatocellular carcinoma recurrence after liver transplantation via inflammatory microenvironment. J Hepatol 2013;58(1):58-64.

7. Kantola T, Klintrup K, Vayrynen JP, Vornanen J, Bloigu R, Karhuet $\mathrm{T}$ el al. Stage-dependent alterations of the serum cytokine pattern in colorectal carcinoma. Br J Cancer 2012;107: 1729-1736.

8. Fonseca FAH, de Oliveira Izar MC. High-Sensitivity C-Reactive Protein and Cardiovascular Disease Across Countries and Ethnicities. Clinics (Sao Paulo). 2016; 71(4): 235-242.

9. Silva D, de Lacerda AP. High-sensitivity C-reactive protein as a biomarker of risk in coronary artery disease. Portuguese J Cardiol 2012; 31(11): 733-745.

10. Yuksel A, Yildiz M, Oylumlu H. Novel markers of endothelial dysfunction and inflammation in Behcet's disease patients with ocular involvement: epicardial fat thickness, carotid intima-me- dia thickness, serum ADMA level, and neutrophil-to-lymphocyte ratio. Clin Rheumatol 2016; 35(3): 701-708.

11. Gong W, Yang Y, Yang X, Guo F, Blood preoperative neutrophilto-lymphocyte ratio is correlated with TNM stage in patients with papillary thyroid cancer. Clinics (Sao Paulo). 2016; 71(6): 311-314.

12. Kasuga J, Kawahara T, Takamoto D. Increased neutrophil-tolymphocyte ratio is associated with disease-specific mortality in patients with penile cancer. BMC Cancer 2016; 16: 396.

13. Nakamura K, Nagasaka T, Nishida T. Neutrophil to lymphocyte ratio in the pre-treatment phase of final-line chemotherapy predicts the outcome of patients with recurrent ovarian cancer. Oncol Lett 2016; 11(6): 3975-3981.

14. Uygur F, Tanriverdi H, Aktop H. The neutrophil-to-lymphocyte ratio in patients with obstructive sleep apnoea syndrome and its relationship with cardiovascular disease," Heart and Lung: Journal of Acute and Critical Care. J Cardiopul Acute Care 2016; 45(2): 121-125.

15. Özpelit E, Akdeniz B, Özpelit ME, Tas S, Bozkurt S, Tertemiz KC, et al. Prognostic value of the neutrophil-to-lymphocyte ratio in pulmonary arterial hypertension. J Int Med Res 2015;43(5):661-671.

16. Kim BJ, Cho SH. The combined impact of neutrophil-to-lymphocyte ratio and type 2 diabetic Mellitus on significant coronary artery disease and carotid artery atherosclerosis. J Cardiovasc Ultrasound 2016; 24(2):115-122.

17. Isaac V, Wu CY, Huang CT, Baune BT, Tseng CL, McLachlan $\mathrm{CS}$, et al. Elevated neutrophil to lymphocyte ratio predicts mortality in medical inpatients with multiple chronic conditions. Medicine (Baltimore) 2016;95(28):e0916.

18. Tamhane UU, Aneja S, Montgomery D, Rogers EK, Eagle EK, Gurm HS. Association between admission neutrophil to lymphocyte ratio and outcomes in patients with the acute coronary syndrome. Am J Cardiol 2008;102:653-657.

19. Sefil F, Ulutas KT, Dokuyucu R, Sumbul AT. Investigation of neutrophil-lymphocyte ratio and blood glucose regulation in patients with type 2 diabetes mellitus. J Int Med Res. 2014;42:581588 .

20. Bahadır A, Baltaci D, Türker Y, Iliev D, Oztuirk S, Deler HM, et al. Is the neutrophil-to-lymphocyte ratio indicative of an inflammatory state in patients with obesity and metabolic syndrome? Anatol J Cardiol. 2015; 15(10): 816-822.

21. Öztürk ZA, Kuyumcu ME, Yesil Y. Is there a link between neutrophil-lymphocyte ratio and microvascular complications in geriatric diabetic patients? J Endocrinol Invest 2013;36(8):593-599.

22. Mertoglu C, Gunay M. Neutrophil-Lymphocyte ratio and Platelet-Lymphocyte ratio as useful predictive markers of prediabetes and diabetes mellitus. Diabetes Metab Syndr 2017;11(1):S127S131.

23. Chittawar S, Dutta D, Qureshi Z, Surana V, Khndare S, Dubey TN, et al. Neutrophil-lymphocyte Ratio is a Novel Reliable Predictor of Nephropathy, Retinopathy, and Coronary Artery Disease in Indians with Type-2 Diabetes. Indian J Endocrinol Metab 2017;21(6):864-870.

24. Khandare SA, Chittawar S, Nahar N, Dubey TN, Qureshi Z. Study of Neutrophil-lymphocyte Ratio as a Novel Marker for Diabetic Nephropathy in Type 2Diabetes. Indian J Endocrinol Metab 2017;21(3):387-392.

25. Forward A, Butt AM, Siddiqui IA, Khalid M, Rubina S, Basit A. Neutrophil-to-lymphocyte ratio and microvascular complications in subjects with type 2diabetes: Pakistan's perspective. Turk J Med Sci. 2018 Feb 23;48(1):157-161.

26. Hussain M, Babar MZM, Akhtar L, Hussain MS. Neutrophil lymphocyte ratio (NLR): A well assessment tool of glycemic control in type 2 diabetic patients. Pak J Med Sci 2017;33(6):1366-1370. 
Table 1: Group statistics analysis and its significance

\begin{tabular}{|c|c|c|c|c|c|c|}
\hline \multirow[b]{2}{*}{ Parameters } & \multicolumn{3}{|c|}{ Group Statistics } & & \multicolumn{2}{|c|}{$\begin{array}{l}95 \% \text { confidence interval of the } \\
\text { difference }\end{array}$} \\
\hline & Sex & Number & Mean (SD) & p-value & Lower & Upper \\
\hline \multirow[t]{2}{*}{ Age } & M & 32 & $46.75(11.08)$ & \multirow{2}{*}{0.8} & \multirow{2}{*}{-11.533} & \multirow{2}{*}{0.67549} \\
\hline & $\mathrm{F}$ & 28 & $52.17(12.53)$ & & & \\
\hline \multirow[t]{2}{*}{ WBC } & M & 31 & $7770.32(1592.84)$ & \multirow{2}{*}{$0.039^{*}$} & \multirow{2}{*}{-1831.7448} & \multirow{2}{*}{-47.6100} \\
\hline & $\mathrm{F}$ & 28 & $8710(1828.84)$ & & & \\
\hline \multirow[t]{2}{*}{ NLR } & M & 32 & $1.87(0.67)$ & \multirow{2}{*}{0.25} & \multirow{2}{*}{-0.51646} & \multirow{2}{*}{0.13699} \\
\hline & $\mathrm{F}$ & 28 & $2.06(0.57)$ & & & \\
\hline \multirow[t]{2}{*}{ hsCRP } & M & 32 & $2.63(3.23)$ & \multirow{2}{*}{$0.026^{*}$} & \multirow{2}{*}{-4.10203} & \multirow{2}{*}{-0.26948} \\
\hline & $\mathrm{F}$ & 28 & $4.81(4.16)$ & & & \\
\hline
\end{tabular}

${ }^{*}$ Correlation is significant at the 0.05 level

Table 2: Correlation hsCRP with WBC and NLR

\begin{tabular}{lcl} 
Correlation of hsCRP with & Correlation Coefficient & p-Value \\
WBC & 0.287 & $0.027^{*}$ \\
NLR & 0.356 & $0.005^{*}$ \\
\hline
\end{tabular}

${ }^{*}$ statistically significant $<0.05$ )

Table 3: Correlation of NLR \& hsCRP with FBS and HbA1c\%

\begin{tabular}{llllc} 
& & WBC & NLR & hsCRP \\
FBS & Correlation Coefficient & 0.253 & 0.167 & 0.114 \\
& p-Value (2-tailed) & 0.053 & 0.201 & 0.386 \\
HbAic\% & Correlation Coefficient & 0.164 & 0.223 & 0.189 \\
& p-Value (2-tailed) & 0.214 & 0.087 & 0.147 \\
\hline
\end{tabular}

